\title{
Screening for point mutations in the LDL receptor gene in Bulgarian patients with severe hypercholesterolemia
}

Received: 20 October 2003/ Accepted: 5 January 2004/Published online: 10 March 2004

(C) The Japan Society of Human Genetics and Springer-Verlag 2004

\begin{abstract}
Familial hypercholesterolemia (FH) is a common, autosomal dominant disorder of lipid metabolism, caused by defects in the receptor-mediated uptake of LDL (low-density lipoproteins) due to mutations in the LDL receptor gene $(L D L R)$. Mutations underlying FH in Bulgaria are largely unknown. The aim of the present study was to provide information about the spectrum of point mutations in $L D L R$ in a sample of 45 Bulgarian patients with severe hypercholesterolemia. Exons 3, 4, 6, 8,9 , and 14 , previously shown to be mutational hot spots in $L D L R$, were screened using PCR-single-strand conformation polymorphism (SSCP). Samples with abnormal SSCP patterns were sequenced. Three different, hitherto undescribed point mutations $(367 \mathrm{~T}>\mathrm{A}$, $377 \mathrm{~T}>\mathrm{A}, \quad 917 \mathrm{C}>\mathrm{A})$ and two previously described mutations $(858 \mathrm{C}>\mathrm{A}$ and $1301 \mathrm{C}>\mathrm{T})$ in eight unrelated patients were identified; four of the detected point mutations being missense mutations and one, a nonsense mutation. One of the newly described point mutations
\end{abstract}

V. A. Mihaylov · A. D. Horvath · V. S. Ganev $(\square)$

Department of Chemistry and Biochemistry,

Medical University of Sofia, 2 Zdrave Str., Sofia,

1431, Bulgaria

E-mail: ganev@medfac.acad.bg

Tel.: + 359-2-9520331

Fax: + 359-2-9541153

A. S. Savov

University Hospital for Obstetrics and Gynaecology,

Medical University of Sofia, 2 Zdrave Str.,

Sofia, 1431, Bulgaria

E. F. Kurshelova · A. R. Goudev

Department of Propaedeutics of Internal Diseases,

Medical University of Sofia, 2 Zdrave Str., Sofia,

1431, Bulgaria

I. D. Paskaleva

National Centre of Cardiovascular Diseases,

Sofia, Bulgaria

I. R. Stoilov

Department of Surgery, University of Connecticut Health Center, Farmington, CT, USA
$(917 \mathrm{C}>\mathrm{A})$ is a base substitution at a nucleotide position, at which two other different base substitutions have already been reported. Thus, all three possible base substitutions at this nucleotide position have been detected, making it a hot spot for point mutations causing $\mathrm{FH}$. This is the first such mutational hot spot described in exon 6 of $L D L R$.

Keywords Familial hypercholesterolemia . LDL receptor $\cdot$ Point mutations

\section{Introduction}

Familial hypercholesterolemia (FH, MIM\#143890) is a common autosomal dominant disorder of lipid metabolism characterized by an elevation in the level of low-density lipoproteins (LDL), the formation of tendon and skin xanthomata, and the development of premature atherosclerosis. It is caused by defects in the receptor-mediated uptake of LDL due to mutations in the LDL receptor gene ( $L D L R)$ (Goldstein et al. 1995). The prevalence of heterozygous $\mathrm{FH}$ in most studied populations is approximately $0.2 \%$. Except for the few populations dominated by founder mutations, the mutations underlying $\mathrm{FH}$ are very heterogeneous, and most affected families are expected to have unique LDLR mutations.

To-date, more than 920 different LDLRmutations have been described worldwide (http://www.umd. necker.fr and http://www.ucl.ac.uk/fh). Of these, about $90 \%$ are point mutations (single base substitutions and small insertions and deletions), the rest being gross rearrangements. Analysis of point mutations distribution reveals clustering in certain coding regions of the $L D L R$.

Currently, FH diagnosis is generally based on clinical presentation and lipid profile. However, clinical presentation of the disease is variable, even among 
patients with the same genetic mutation, and clinical symptoms of the disease may not always be apparent, especially in young adults and children. Furthermore, lipid values for heterozygous FH patients and unaffected relatives may overlap (Williams et al. 1993). Therefore, a specific molecular diagnosis of these types of hypercholesterolemia is desirable in order to definitively diagnose $\mathrm{FH}$ patients and track the mutation within the affected family. In addition, recent studies have shown a relation between the presence of specific mutations and response to lipid lowering therapy (Jeenah et al. 1993; Leitersdorf et al. 1993; Couture et al. 1998; Sun et al. 1998; Heath et al. 1999). Thus, the molecular approach helps in stratifying the patient's risk individually and possibly selecting the most effective treatment.

Mutations underlying $\mathrm{FH}$ in Bulgaria are largely unknown, but a broad spectrum of mutations in $L D L R$ is expected, given the genetic heterogeneity of the Bulgarian population - well known from studies of other genes (Kalaydjieva et al. 1992; Bronzova et al. 1994; Angelicheva et al. 1997). The present report provides the first data about the point mutation spectrum in six exons of $L D L R$, known to harbor more than $60 \%$ of the mutations in other population groups. A sample of 45 Bulgarian unrelated patients with severe hypercholesterolemia was studied, using single-strand conformation polymorphism (SSCP) analysis (Orita et al. 1989; Jordanova et al. 1997), followed by direct sequencing, and three different, hitherto undescribed and two previously described mutations were found in eight unrelated patients.

\section{Materials and methods}

Subjects

This study comprises a group of 45 unrelated patients (20 female and 25 male) with severe hypercholesterolemia (total plasma cholesterol level above $8.5 \mathrm{mmol} / 1$ prior to treatment). The lipid profile of our group is shown in Table 1. All participants gave their informed consent to participate in the study, and the study protocol has been approved by the IRB of the Medical University of Sofia, Bulgaria. None of the 45 subjects studied was carrier of the most common single mutation resulting in hypercholesterolemia, $A P O B$ $\mathrm{R} 3500 \mathrm{Q}$, or any other mutations in the receptor-binding region of APOB (Horvath et al. 2001).

\section{DNA analysis}

Genomic DNA was extracted from peripheral blood cells as described previously (Miller et al. 1988). Exons 3, 4, 6, 8, 9, and 14 of $L D L R$ were amplified by PCR using primers according to Jensen et al. (1996) and subjected to mutation screening using a modified, nonradioactive, high-sensitivity SSCP method (Jordanova et al. 1997). Samples exhibiting mobility shifts were sequenced by radioactive labeling with the Sequenase 2.0 PCR Product Sequencing Kit (Amersham/USB) in both directions using the amplification primers.

\section{Results and discussion}

We analyzed 45 patients with severe hypercholesterolemia. Exons 3, 4, 6, 8, 9, and 14, shown to be mutational hot spots in the $L D L R$, were screened using PCR-SSCP. These exons constitute a region over which more than $60 \%$ of all known point mutations in the $L D L R$ are located (http://www.umd.necker.fr and http://www. ucl.ac.uk/fh).

DNA sequencing of the samples showing aberrant SSCP patterns detected five different mutations in three exons (exons 4, 6, and 9) in eight unrelated patients, all of them in a heterozygous state. The mutations detected in our sample are summarized in Table 2. Three of the mutations $(367 \mathrm{~T}>\mathrm{A}, 377 \mathrm{~T}>\mathrm{A}$, and $917 \mathrm{C}>\mathrm{A})$ are described for the first time and the rest $(858 \mathrm{C}>\mathrm{A}$ and $1301 \mathrm{C}>\mathrm{T}$ ) have been previously found in other populations (Hobbs et al. 1992; Webb et al. 1996; Day et al. 1997; Mavroidis et al. 1997; Nauck et al. 2001; Wang et al. 2001). These nucleotide changes constitute four missense mutations (S102T, F105Y, S265R, and $\mathrm{T} 413 \mathrm{M})$ and one nonsense mutation (S285X).
Table 1 Lipid profile of 45 Bulgarian hypercholesterolemic subjects studied for point mutations in the $L D L R$. Values are mean $\pm \mathrm{SD}$

\begin{tabular}{llllll}
\hline Subjects & TC $(\mathrm{mmol} / \mathrm{l})$ & LDL-C $(\mathrm{mmol} / \mathrm{l})$ & HDL-C $(\mathrm{mmol} / \mathrm{l})$ & TG $(\mathrm{mmol} / \mathrm{l})$ & Age (years) \\
\hline$n=45$ & $10.81 \pm 2.23$ & $7.68 \pm 2.51$ & $1.26 \pm 0.55$ & $3.9 \pm 2.98$ & $47.2 \pm 9.7$ \\
\hline
\end{tabular}

Table 2 Point mutations in the $L D L R$ identified in Bulgarian hypercholesterolemic subjects

\begin{tabular}{|c|c|c|c|c|c|}
\hline Nucleotide change & Codon change & $\begin{array}{l}\text { Amino acid } \\
\text { change }\end{array}$ & Location & $\begin{array}{l}\text { Number of carriers } \\
\text { (proportion } \pm \text { SE) }\end{array}$ & Reference \\
\hline $367 \mathrm{~T}>\mathrm{A}$ & $\mathrm{TCT}>\mathrm{ACT}$ & $\mathrm{S} 102 \mathrm{~T}$ & Exon 4 & $2(0.04 \pm 0.03)$ & This study \\
\hline $377 \mathrm{~T}>\mathrm{A}$ & $\overline{\mathrm{TTC}}>\overline{\mathrm{T} A C}$ & F105Y & Exon 4 & $1(0.02 \pm 0.02)$ & This study \\
\hline $858 \mathrm{C}>\mathrm{A}$ & $\mathrm{A} \overline{\mathrm{G}} \underline{\mathrm{C}}>\overline{\mathrm{AG}} \underline{\mathrm{A}}$ & S265R & Exon 6 & $3(0.07 \pm 0.04)$ & $\begin{array}{l}\text { Hobbs et al. (1992), Webb } \\
\text { et al. (1996), Day et al. (1997), } \\
\text { Mavroidis et al. (1997), and } \\
\text { Nauck et al. (2001) }\end{array}$ \\
\hline $917 \mathrm{C}>\mathrm{A}$ & TCA $>$ TAA & S285X & Exon 6 & $1(0.02 \pm 0.02)$ & This study \\
\hline $1301 \mathrm{C}>\mathrm{T}$ & $\mathrm{A} \underline{\bar{C}} \mathrm{G}>\mathrm{A} \overline{\bar{T}} \mathrm{G}$ & $\mathrm{T} 413 \mathrm{M}$ & Exon 9 & $1(0.02 \pm 0.02)$ & Wang et al. (2001) \\
\hline
\end{tabular}


Table 3 Genotype-phenotype comparisons in the Bulgarian heterozygous familial hypercholesterolemia subjects

\begin{tabular}{lcllll}
\hline Mutation & TC (mmol/l) & LDL-C (mmol/l) & HDL-C (mmol/l) & TG (mmol/l) & Age (years) \\
\hline $367 \mathrm{~T}>$ A, S102T & 8.59 & 6.71 & 1.22 & 2.91 & 43 \\
367T > A, S102T & 8.50 & 7.05 & 1.13 & 1.75 & 60 \\
377T > A, F105Y & 9.44 & 7.70 & 1.44 & 0.58 & 60 \\
$858 \mathrm{C}>$ A, S265R & 11.31 & 8.53 & 0.72 & 4.50 & 50 \\
$858 \mathrm{C}>$ A, S265R & 11.00 & 9.06 & 0.80 & 2.50 & 49 \\
$858 \mathrm{C}>$ A, S265R & 9.20 & 6.60 & 1.78 & 1.80 & 64 \\
$917 \mathrm{C}$ > A, S285X & 12.90 & 9.15 & 2.18 & 2.89 & 36 \\
$1301 \mathrm{C}>$ T, T413M & 9.30 & 6.78 & 1.21 & 2.82 & 50 \\
$x \pm$ SD & $10.02 \pm 1.55$ & $7.70 \pm 1.08$ & $1.31 \pm 0.49$ & $2.47 \pm 1.14$ & $51.5 \pm 9.44$ \\
\hline
\end{tabular}

Three new mutations in $L D L R$ were found in Bulgarian FH patients. Screening of 120 chromosomes from healthy Bulgarians by SSCP did not reveal carriers of these mutations, suggesting that these are more likely disease causing mutations rather than polymorphisms.

The missense mutation S102T was identified in two unrelated patients. This sequence variation is not supposed to lead to a change in charge or hydrophobicity because of the appreciable structural similarity between the wild type and mutant amino acids (Ser102 substituted by Thr). This is why we expect only a partial impact of the change on LDLR protein conformation, and therefore, on its ligand-binding ability. Indeed, both carriers of this mutation exhibit levels of total serum cholesterol and LDL cholesterol in the lower range of our group: TC, 8.59 and $8.50 \mathrm{mmol} / \mathrm{l}$; LDL-C, 6.71 and $7.05 \mathrm{mmol} / 1$, respectively (Table 3 ). Also, they present a milder phenotype of familial hypercholesterolemia-no apparent xanthomas in both of them, and coronary heart disease in one of them.

The mutation F105Y in exon 4 leads to the replacement of the hydrophobic amino acid phenylalanine by the hydrophilic amino acid tyrosine in repeat 3 of the LDLR binding domain. This change in hydrophobicity may affect the conformation of this domain. The clinical symptoms of FH are more severe in comparison with the carriers of the closely located mutation S102T, with higher values of serum TC and LDL-C (Table 3), advanced coronary heart disease, and prominent arcus corneae.

The newly identified nonsense mutation in exon 6, S285X, gives rise to a premature stop codon in repeat seven of the LDLR-binding domain so that the mutant receptor protein would lack all domains carboxyterminal to the ligand-binding domain. Accordingly, the S285X allele has to be classified as a null-allele. Indeed, the carrier of this newly described mutation in $L D L R$ has most severe clinical manifestations of familial hypercholesterolemia-highest levels of total serum cholesterol and LDL cholesterol among all mutation carriers, 12.90 and $9.15 \mathrm{mmol} / 1$, respectively (Table 3), severe coronary heart disease, and multiple xanthomas.

Our analysis of both most updated and comprehensive $L D L R$ mutation databases (http://www.ucl.ac.uk/ fh; http://www.umd.necker.fr) identified 480 unique, single base substitutions in the coding sequence.
Interestingly, one of the newly described mutations in this study (S285X) is caused by a substitution at a nucleotide position where other mutations have already been reported (Hobbs et al. 1992; Schuster and Humphries 1994; Lombardi et al. 1995; Pimstone et al. 1997; Jensen et al. 1999; Lombardi et al. 2000; Kuhrova et al. 2001, 2002). The mutation S285X identified in our study is caused by a substitution of cytosine by adenine $(917 \mathrm{C}>\mathrm{A})$, whereas the two other substitutions at the same position identified earlier by other groups are another nonsense mutation $917 \mathrm{C}>\mathrm{G}$ (Kuhrova et al. 2001, 2002), and a missense mutation 917C > T (S285L, known as FH Amsterdam) (Hobbs et al. 1992; Schuster and Humphries 1994; Lombardi et al. 1995; Pimstone et al. 1997; Jensen et al. 1999; Lombardi et al. 2000). Consequently, nucleotide position 917 of $L D L R$ can be described as a hot spot for point mutations causing FH. This is the first reported mutational hot spot in exon 6 with all three possible base substitutions at the same nucleotide position; nine other such hot spots have been reported so far throughout the other 17 exons of the gene.

In summary, we have detected point mutations explaining elevated LDL levels in 8 out of 45 analyzed patients with hypercholesterolemia (frequency $0.18 \pm 0.06$ ). These eight patients were found to be carriers of five different point mutations. None of the patients was detected to be a carrier of more than one nucleotide alteration.

Acknowledgement This work was supported by the Medical Research Council at the Medical University of Sofia (grant 024/2002).

\section{References}

Angelicheva D, Calafell F, Savov A, Jordanova A, Kufardjieva A, Galeva I, Nedkova V, Ivanova T, Yankova P, Konstantinova D, Genev E, Kalaydjieva L (1997) Cystic fibrosis mutations and associated haplotypes in Bulgaria-a comparative population genetic study. Hum Genet 99:513-520

Bronzova J, Todorova A, Kalaydjieva L (1994) Detection of carriers of deletions in the dystrophin gene in Bulgarian DMD BMD families. Hum Genet 93:170-174

Couture P, Brun LD, Szots F, Lelievre M, Gaudet D, Despres JP, Simard J, Lupien PJ, Gagne C (1998) Association of specific LDL-receptor gene mutations with differential plasma lipoprotein response to simvastatin in young French Canadians with heterozygous familial hypercholesterolemia. Arterioscler Thromb Vasc Biol 18:1007-1012 
Day IN, Whittall RA, O'Dell SD, Haddad L, Bolla MK, Gudnason V, Humphries SE (1997) Spectrum of LDL receptor gene mutations in heterozygous familial hypercholesterolemia. Hum Mutat 10:116-127

Goldstein JL, Hobbs HH, Brown MS (1995) Familial hypercholesterolemia. In: Scriver CR, Beaudet AL, Sly WS, Valle D (eds) The metabolic basis of inherited disease, 7th edn. McGraw-Hill, New York, pp 1981-2030

Heath KE, Gudnason V, Humphries SE, Seed M (1999) The type of mutation in the low density lipoprotein receptor gene influences the cholesterol-lowering response of the HMG-CoA reductase inhibitor simvastatin in patients with heterozygous familial hypercholesterolaemia. Atherosclerosis 143:41-54

Hobbs HH, Brown MS, Goldstein JL (1992) Molecular genetics of the LDL receptor gene in familial hypercholesterolemia. Hum Mutat 1:445-466

Horvath A, Savov A, Kirov S, Karshelova E, Paskaleva I, Goudev A, Ganev V (2001) High frequency of the ApoB-100 R3500Q mutation in Bulgarian hypercholesterolaemic subjects. J Med Genet 38:536-540

Jeenah M, September W, Graadt van Roggen F, de Villiers W, Seftel H, Marais D (1993) Influence of specific mutations at the LDL-receptor gene locus on the response to simvastatin therapy in Afrikaner patients with heterozygous familial hypercholesterolaemia. Atherosclerosis 98:51-58

Jensen HK, Jensen LG, Hansen PS, Faergeman O, Gregersen N (1996) High sensitivity of the single-strand conformation polymorphism method for detecting sequence variations in the low-density lipoprotein receptor gene validated by DNA sequencing. Clin Chem 42:1140-1146

Jensen HK, Jensen LG, Meinertz H, Hansen PS, Gregersen N, Faergeman O (1999) Spectrum of LDL receptor gene mutations in Denmark: implications for molecular diagnostic strategy in heterozygous familial hypercholesterolemia. Atherosclerosis $146: 337-344$

Jordanova A, Kalaydjieva L, Savov A, Claustres M, Schwarz M, Estivill X, Angelicheva D, Haworth A, Casals T, Kremensky I (1997) SSCP analysis: a blind sensitivity trial. Hum Mutat 10:65-70

Kalaydjieva L, Dworniczak B, Kremensky I, Koprivarova K, Radeva B, Milusheva R, Aulehla-Scholz C, Horst J (1992) Heterogeneity of mutations in Bulgarian phenylketonuria haplotype 1 and 4 alleles. Clin Genet 41:123-128

Kuhrova V, Francova H, Zapletalova P, Freiberger T, Fajkusova L, Hrabincova E, Slovakova R, Kozak L (2001, 2002) Spectrum of low density lipoprotein receptor mutations in Czech hypercholesterolemic patients. Hum Mutat 18:253. Corrected and republished in Hum Mutat 19:80

Leitersdorf E, Eisenberg S, Eliav O, Friedlander Y, Berkman N, Dann EJ, Landsberger D, Sehayek E, Meiner V, Wurm M, Bard JM, Fruchart JC, Stein Y (1993) Genetic determinants of responsiveness to the $\mathrm{HMG}-\mathrm{CoA}$ reductase inhibitor fluvastatin in patients with molecularly defined heterozygous familial hypercholesterolemia. Circulation 87:35-44
Lombardi P, Sijbrands EJ, van de Giessen K, Smelt AH, Kastelein JJ, Frants RR, Havekes LM (1995) Mutations in the low density lipoprotein receptor gene of familial hypercholesterolemic patients detected by denaturing gradient gel electrophoresis and direct sequencing. J Lipid Res 36:860-867

Lombardi MP, Redeker EJ, Defesche JC, Kamerling SW, Trip MD, Mannens MM, Havekes LM, Kastelein JJ (2000) Molecular genetic testing for familial hypercholesterolemia: spectrum of LDL receptor gene mutations in The Netherlands. Clin Genet 57:116-124

Mavroidis N, Traeger-Synodinos J, Kanavakis E, Drogari E, Matsaniotis N, Humphries S, Day I, Kattamis C (1997) A high incidence of mutations in exon 6 of the low-density lipoprotein receptor gene in Greek familial hypercholesterolemia patients, including a novel mutation. Hum Mutat 9:274-276

Miller SA, Dykes DD, Polesky HF (1988) A simple salting out procedure for extracting DNA from human nucleated cells. Nucleic Acids Res 16:1215

Nauck MS, Koster W, Dorfer K, Eckes J, Scharnagl H, Gierens H, Nissen H, Nauck MA, Wieland H, Marz W (2001) Identification of recurrent and novel mutations in the LDL receptor gene in German patients with familial hypercholesterolemia. Hum Mutat 18:165-166

Orita M, Iwahana H, Kanazawa H, Hayashi K, Sekiya T (1989) Detection of polymorphisms of human DNA by gel electrophoresis as single-strand conformation polymorphisms. Proc Natl Acad Sci USA 86:2766-2770

Pimstone SN, Defesche JC, Clee SM, Bakker HD, Hayden MR, Kastelein JJ (1997) Differences in the phenotype between children with familial defective apolipoprotein B-100 and familial hypercholesterolemia. Arterioscler Thromb Vasc Biol 17:826-833

Schuster H, Humphries S (1994) European workshop on LDL receptor defects. European Working Group on Familial Hypercholesterolaemia. Clin Investig 72:898-907

Sun XM, Patel DD, Knight BL, Soutar AK (1998) Influence of genotype at the low density lipoprotein (LDL) receptor gene locus on the clinical phenotype and response to lipid-lowering drug therapy in heterozygous familial hypercholesterolaemia. The Familial Hypercholesterolaemia Regression Study Group. Atherosclerosis 136:175-185

Wang J, Huff E, Janecka L, Hegele RA (2001) Low density lipoprotein receptor (LDLR) gene mutations in Canadian subjects with familial hypercholesterolemia, but not of French descent. Hum Mutat 18:359

Webb JC, Sun XM, McCarthy SN, Neuwirth C, Thompson GR, Knight BL, Soutar AK (1996) Characterization of mutations in the low density lipoprotein (LDL)-receptor gene in patients with homozygous familial hypercholesterolemia, and frequency of these mutations in $\mathrm{FH}$ patients in the United Kingdom. J Lipid Res 37:368-381

Williams RR, Hunt SC, Schumacher MC, Hegele RA, Leppert MF, Ludwig EH, Hopkins PN (1993) Diagnosing heterozygous familial hypercholesterolemia using new practical criteria validated by molecular genetics. Am J Cardiol 72:171-176 